who smoked in pregnancy are at almost a fivefold increased risk of the sudden infant death syndrome compared with infants of non-smokers. ${ }^{2}$ The effect of environmental exposure to tobacco smoke is less clear. A meta-analysis of studies in which the mother did not smoke but the father did found the risk was increased 1.4-fold compared with non-smoking parents. ${ }^{2}$ Now that few infants sleep prone maternal smoking is the major risk factor. The challenge is to develop effective strategies to reduce smoking in pregnancy as simply telling mothers that their babies are at increased risk of the sudden infant death syndrome is ineffective at changing behaviour.

Thermal stress has been implicated and has led to the advice not to let baby get too hot. Recent work suggests that excessive clothing or bedding increases the risk only in infants who sleep prone. Infants are at increased risk of thermal stress when sleeping prone because the face, which is the most important skin surface for heat loss, is partially insulated by the mattress. ${ }^{3}$ Thermal factors are no longer important as few babies sleep prone; head covering and rebreathing are alternative, more likely explanations for the finding of an increased risk for babies sleeping under heavy duvets.

Other prevention messages have been promoted but with less agreement. Breast feeding is thought to reduce the risk in New Zealand, but in the United Kingdom the association is attributed to socioeconomic confounding. Pacifiers (dummies) are associated with a reduced risk, and their use is promoted in the
Netherlands, ${ }^{4}$ whereas in other countries there is concern that their use might be associated with undesirable effects, such as reduction in breast feeding. ${ }^{5}$

In this paper Blair et al have shown that infants who share a sofa with an adult were at particularly high risk of the sudden infant death syndrome, but it accounts for only $6 \%$ of all cases. There was no increased risk with bed sharing for infants of mothers who were non-smokers. Also there was no increased risk associated with bed sharing when the infant was placed back in his or her cot, but this ignores the fact that many parents unintentionally fall asleep with their baby in their bed. In contrast $23 \%$ of deaths in their study occurred among cosleeping infants of mothers who smoke. This confirms work from New Zealand, United States, Scotland, and Nordic countries. ${ }^{1}$ It is time to recommend that mothers who smoke should not share a bed with their babies.

Scragg RKR, Mitchell EA. Side sleeping position and bed sharing in the sudden infant death syndrome. Ann Med 1998;30:345-9.

2 Mitchell EA, Milerad J. Smoking and sudden infant death syndrome. In: Tobacco Free Initiative. International consultation on environmental tobacco smoke (ETS) and child health. Geneva: World Health Organisation, 1999:105-29.

3 Nelson EA, Taylor BJ, Weatherall IL. Sleeping position and infant bedding may predispose to hyperthermia and the sudden infant death syndrome. Lancet 1989;i:199-201

4 L'Hoir MP, Engelberts AC, van Well GThJ, McClelland S, Westers P, Danachli $\mathrm{T}$, et al. Risk and preventive factors for cot death in the Netherlands, a low-incidence country. Eur J Pediatr 1998;157:681-8.

5 Fleming PJ, Blair PS, Pollard K, Platt MW. Leach C, Smith I, et al. Pacifier use and sudden infant death syndrome: results from the CESDI/SUDI case control study. Arch Dis Child 1999;81:112-6.

\title{
Increase in congenital rubella occurrence after immunisation in Greece: retrospective survey and systematic review
}

\author{
Takis Panagiotopoulos, Ioanna Antoniadou, Eleni Valassi-Adam
}

\section{Editorial by King \\ Correspondence to: T Panagiotopoulos tpan@ath.forthnet.gr \\ continued over}

BMJ 1999;319:1462-7

website

extra

Details and references of the trials appear on the BMJ's website

www.bmj.com

\section{Abstract}

Objective To describe the events leading to the epidemic of congenital rubella syndrome in Greece in 1993 after a major rubella epidemic.

Design Retrospective survey and systematic review. Setting Greece (population 10 million), 1950-95. Subjects Children, adolescents, and women of childbearing age.

Results Around 1975 in Greece the measles, mumps, and rubella vaccine started being given to boys and girls aged 1 year without policies to attain high vaccination coverage and to protect adolescents and young women. During the 1980 s, vaccination coverage for rubella remained consistently below $50 \%$, and the proportion of pregnant women susceptible to rubella gradually increased. In 1993 the incidence of rubella in young adults was higher than in any previous epidemic year. The epidemic of congenital rubella that followed, with 25 serologically confirmed cases (24.6 per 100000 live births), was probably the largest such epidemic in Greece after 1950.
Conclusions With low vaccination coverage, the immunisation of boys and girls aged 1 year against rubella carries the theoretical risk of increasing the occurrence of congenital rubella. This phenomenon, which has not been previously reported, occurred in Greece.

\section{Introduction}

Rubella is usually a mild disease, but infection during the first 3-4 months of pregnancy can result in spontaneous abortion, stillbirth, and congenital rubella syndrome. $^{12}$

Immunisation programmes to prevent congenital rubella syndrome were introduced in many countries soon after vaccines for rubella and measles, mumps, and rubella became available in 1969 and 1971 respectively. ${ }^{3}$ The immunisation of boys and girls aged 1 year ("indirect" strategy) aims to protect women of childbearing age from exposure to the rubella virus by interrupting its transmission. ${ }^{45}$ This can lead to a rapid reduction in cases of congenital rubella, but if vaccina- 
tion coverage is low there is concern that this strategy may increase the incidence of rubella in adolescents and adults thus increasing the incidence of congenital rubella. ${ }^{4-9}$ It has been estimated that in developed countries this could happen in the long term if immunisation uptake was lower than $50 \%-60 \%$, with wide oscillations in the incidence of congenital rubella in the medium term. ${ }^{49}$ In contrast, the immunisation of adolescent girls ("direct" strategy) does not interfere appreciably with the transmission of the virus and aims to protect women of childbearing age from the disease. ${ }^{410}$ Several countries have adopted a two dose vaccination strategy because of its advantages. ${ }^{11-14}$

Some less developed countries have recently introduced rubella immunisation into their national schedules, or are considering doing so. ${ }^{14}{ }^{15}$ The elimination of indigenous congenital rubella syndrome in Europe by the year 2000 is part of the World Health Organisation's health for all strategy. ${ }^{16}$

In Greece, immunisation of boys and girls aged 1 year with the measles, mumps, and rubella vaccine was introduced in the mid-1970s but not as part of a systematic policy. ${ }^{17}$ In 1993 a major rubella epidemic took place, which was followed by the birth of a large number of babies with congenital rubella. We hypothesised that this epidemic was related to immunisation practices. As there is no systematic surveillance for rubella in Greece we reviewed relevant information and delineated the events leading to this epidemic.

\section{Methods}

We sought all available information on immunisation policies and practices, vaccination coverage, serologically detected immunity, and the occurrence of rubella and congenital rubella in Greece.

We carried out a systematic review of the Greek medical literature by searching electronically the IATROTEK (1980-96) and the Athens Institute of Child Health (1979-96) databases for publications on rubella and congenital rubella, and by hand searching paediatric and other major medical journals published in Greece (1950-97) and proceedings of the annual panhellenic paediatric and medical conferences (197597). We also retrieved relevant publications cited in papers identified from these sources. All the studies identified were included, and we systematically evaluated the studies on vaccination coverage and serologically detected immunity, using as criteria the adequacy of documentation of methods, the study population, and the representativeness and size of the sample.

We assessed official documents and unpublished data of the Greek Ministry of Health and other public and private agencies for the period 1970-95. Notifications of rubella cases and mortality from rubella and congenital rubella for the years 1960-95 were examined with data from the National Statistical Service of Greece. ${ }^{18}$

\section{Results}

\section{Immunisation policies}

Vaccines against rubella and measles, mumps, and rubella became commercially available in Greece around $1975 .^{19}$ Since 1977 eminent Greek paediatri-

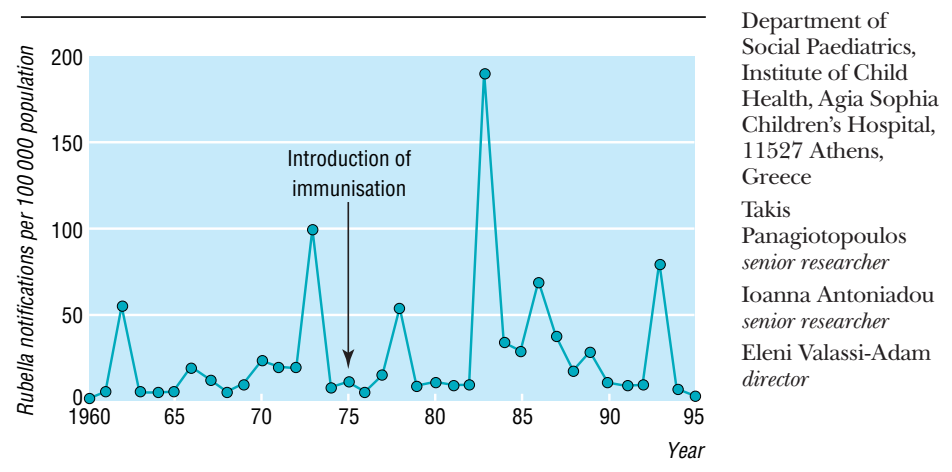

Fig 1 Notifications of rubella in Greece, 1960-95. Source: National Statistical Service of Greece ${ }^{18}$

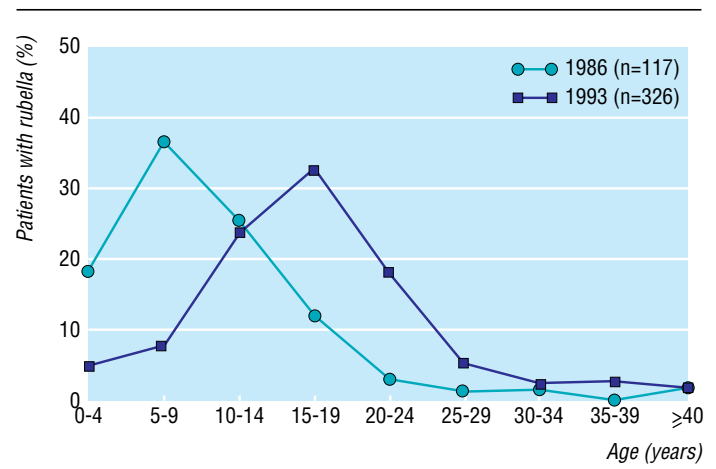

Fig 2 Age distribution of patients with rubella attending outpatient departments of general hospital in greater Athens, 1986 and 1993. Source: Panagiotopoulos et al $1996^{20}$

cians have recommended that children be immunised with the measles, mumps, and rubella vaccine at the age of 15 months. ${ }^{\mathrm{w} 1 \mathrm{w} 2}$ This started in the private sector, which was used by an estimated $56 \%$ of children in Athens in the late $1970 \mathrm{~s} .{ }^{\mathrm{w} 3}$ Because rubella vaccination was classed as "optional" by the Ministry of Health at this time public services offered rubella immunisation on request only to girls aged $10-14$ years. ${ }^{\mathrm{w} 4}$ A limited rubella vaccination programme for adolescent girls and special groups of young women was introduced in 1980. ${ }^{\mathrm{w4}}$ In 1975-80 the uptake of vaccination for measles in the second year of life, introduced in the late 1960 s, was $1 \%, 5 \%, 10 \% 18 \%, 19 \%$, and $43 \%$ in various groups of children. ${ }^{\text {w3 w5-w8 }}$

The national immunisation schedule was revised in 1987, but the new scheme gave doctors the option of vaccinating children aged 15 months with the measles monovalent vaccine or the measles, mumps, and rubella vaccine, and it included no recommendation for the vaccination of adolescent girls or young women for rubella. ${ }^{\text {w9 }}$ In 1989 the Ministry of Health declared the immunisation of all children for measles, mumps, and rubella aged 1 "compulsory"w10 and this was extended to the public sector. In 1991 a two dose vaccination scheme (at 15 months and 11-12 years) was adopted for boys and girls. ${ }^{\mathrm{w} 11}$ No policy has ever been introduced to vaccinate susceptible women postpartum.

Rubella has been a notifiable disease in Greece since the $1950 \mathrm{~s}$, but notification is not comprehensive and the age of cases notified is not reported..$^{18}$ The 
Main characteristics of newborns with confirmed congenital rubella syndrome recorded during epidemic in Greece, 1993*. Modified from Panagiotopoulos et $\mathrm{a}^{22}$

\begin{tabular}{|c|c|c|c|c|}
\hline $\begin{array}{l}\text { Month of } \\
\text { birth (sex) }\end{array}$ & Region of residence & $\begin{array}{l}\text { Age (months) at } \\
\text { diagnosis }\end{array}$ & Clinical and laboratory manifestations reported $\dagger$ & Died (age) $\ddagger$ \\
\hline \multicolumn{5}{|l|}{ July } \\
\hline Male & Aegean islands & $<1$ & Patent ductus arteriosus, developmental retardation, cryptorchidism & - \\
\hline Male & Greater Athens & $<1$ & Thrombocytopenic purpura, seizures & - \\
\hline \multicolumn{5}{|l|}{ August } \\
\hline Female & Greater Athens & 3 & $\begin{array}{l}\text { Pulmonary artery stenosis and hypoplasia, patent ductus arteriosus, } \\
\text { cataract, hypertonia, intracranial calcifications, failure to thrive }\end{array}$ & - \\
\hline Unknown & Macedonia & $<1$ & $\begin{array}{l}\text { Hepatosplenomegaly, pigmentary retinopathy, hypotonia, developmental } \\
\text { retardation, prematurity }\end{array}$ & - \\
\hline Unknown & Macedonia & $<1$ & $\begin{array}{l}\text { Hepatosplenomegaly, corneal opacity, petechiae, thrombocytopenia, } \\
\text { maculopapular rash, radiographic bone lucencies, hypotonia, intrauterine } \\
\text { growth retardation, prematurity, failure to thrive, anaemia }\end{array}$ & 4 months \\
\hline \multicolumn{5}{|l|}{ September } \\
\hline Female & Crete & $<1$ & $\begin{array}{l}\text { Patent ductus arteriosus, ventricular septal defect, intrauterine growth } \\
\text { retardation }\end{array}$ & - \\
\hline Male & Greater Athens & $<1$ & Thrombocytopenic purpura, intrauterine growth retardation, prematurity & - \\
\hline Male & Greater Athens & $<1$ & Patent ductus arteriosus, petechiae, thrombocytopenia & - \\
\hline Female & Aegean islands & $<1$ & $\begin{array}{l}\text { Patent ductus arteriosus, atrial and ventricular septal defect, } \\
\text { microphthalmia, macular rash, jaundice, hypertonia, large anterior fontanelle }\end{array}$ & 1 month \\
\hline \multicolumn{5}{|l|}{ October } \\
\hline Male & $\begin{array}{l}\text { Rest of Central Greece } \\
\text { and Evia§ }\end{array}$ & $<1$ & $\begin{array}{l}\text { Cataract, glaucoma, ventricular septal defect, intrauterine growth retardation, } \\
\text { failure to thrive }\end{array}$ & - \\
\hline Female & Greater Athens & $<1$ & $\begin{array}{l}\text { Microcephaly, patent ductus arteriosus, atrial septal defect, } \\
\text { thrombocytopenic purpura, hepatomegaly, jaundice }\end{array}$ & $<1$ month \\
\hline Female & Aegean islands & $<1$ & Patent ductus arteriosus, cataract, microphthalmia, intracranial calcifications & - \\
\hline Female & Greater Athens & 5 & Tetralogy of Fallot, cataract & - \\
\hline Male & Greater Athens & $<1$ & $\begin{array}{l}\text { Patent ductus arteriosus, atrial and ventricular septal defect, radiographic } \\
\text { bone lucencies, intrauterine growth retardation }\end{array}$ & - \\
\hline Male & Peloponnissos & $<1$ & $\begin{array}{l}\text { Patent ductus arteriosus, tricuspid insufficiency, thrombocytopenic purpura, } \\
\text { hepatomegaly, jaundice, hearing loss, prematurity }\end{array}$ & $<1$ month \\
\hline Male & Greater Athens & $<1$ & Cataract, glaucoma, midline cerebral cyst & - \\
\hline \multicolumn{5}{|l|}{ November } \\
\hline Female & Greater Athens & $<1$ & Ebstein anomaly, cataract & $<1$ month \\
\hline Male & $\begin{array}{l}\text { Rest of Central Greece } \\
\text { and Evia§ }\end{array}$ & 1 & $\begin{array}{l}\text { Patent ductus arteriosus, cataract, microphthalmia, hepatosplenomegaly, } \\
\text { thrombocytopenia, anaemia }\end{array}$ & - \\
\hline Female & Aegean Islands & $<1$ & Patent ductus arteriosus, cataract, hearing loss & - \\
\hline Female & Crete & $<1$ & Congenital heart disease (unspecified), cataract, hydrocephalus & $<1$ month \\
\hline Male & Ipiros & 2 & Patent ductus arteriosus, cataract, petechiae, hepatosplenomegaly, seizures & - \\
\hline Female & Greater Athens & 5 & $\begin{array}{l}\text { Hepatosplenomegaly, seizures, hypotonia, intracranial calcifications, } \\
\text { intrauterine growth retardation, failure to thrive }\end{array}$ & 5 months \\
\hline \multicolumn{5}{|l|}{ December } \\
\hline Female & $\begin{array}{l}\text { Rest of Central Greece } \\
\text { and Evia§ }\end{array}$ & $<1$ & $\begin{array}{l}\text { Patent ductus arteriosus, thrombocytopenic purpura, hepatomegaly, hearing } \\
\text { loss, intrauterine growth retardation }\end{array}$ & - \\
\hline Male & Peloponnissos & 1 & $\begin{array}{l}\text { Patent ductus arteriosus, jaundice, pneumonitis, hearing loss, } \\
\text { developmental retardation, prematurity, failure to thrive }\end{array}$ & - \\
\hline Male & Thessalia & $<1$ & Pulmonary artery stenosis, atrial septal defect, cataract & - \\
\hline
\end{tabular}

*Period of investigation: 1 July 1993 to 31 June 1994. Confirmed cases reported from nine hospitals. †All cases positive for rubella specific IgM antibodies. ‡Death within period of investigation. §Rest of Central Greece and Evia is one of the 10 regions of Greece.

introduction of rubella immunisation did not change this nor was any surveillance system for congenital rubella syndrome established.

\section{Vaccination coverage and serologically detected immunity}

Vaccination uptake by children is not assessed systematically in Greece. Several studies have been carried out with different methodologies. We identified 18 published studies reporting coverage for rubella vaccination before 1993 (see table A on website). ${ }^{\text {w5-w8 w12-w25 }}$ These studies showed that during the late 1970 s and the 1980s vaccination coverage for rubella increased only slowly, remaining consistently below $50 \%$, and did not reach 50\%-60\% before 1990 .

Although 17 serological studies on rubella immunity were identified (see table B on website), ${ }^{\mathrm{w} 7}$ w26-w41 only five, which studied populations of pregnant women in Athens, are comparable. These show a gradual increase in the proportion of pregnant women susceptible to rubella during the 1980s: $12 \%(1971-5)$, $11 \%$ (1980), 17\% (1981), 24\% (1984-9), and 36\% $(1990-1){ }^{\text {w28 } 833 \text { w35 w37 w40 }}$

\section{Rubella and congenital rubella syndrome}

For several years after the introduction of the immunisation of children aged 1 year no substantial changes in the incidence of rubella, as reflected by notified cases, were observed in Greece, and major epidemics continued to occur (fig 1). ${ }^{18}$ Data on the age distribution of cases are limited. A large study on reported morbidity in the early 1960s in Athens estimated that the mean age at infection was 8.5 years, ${ }^{\mathrm{w} 42}$ and a subsequent serological study of immunity to rubella gave accordant results. ${ }^{\text {w26 }}$ The age of patients with rubella attending health services in the province of Attiki (Athens and its surrounds) in 1993 and in previous years was studied retrospectively; a shift in the age distribution towards 


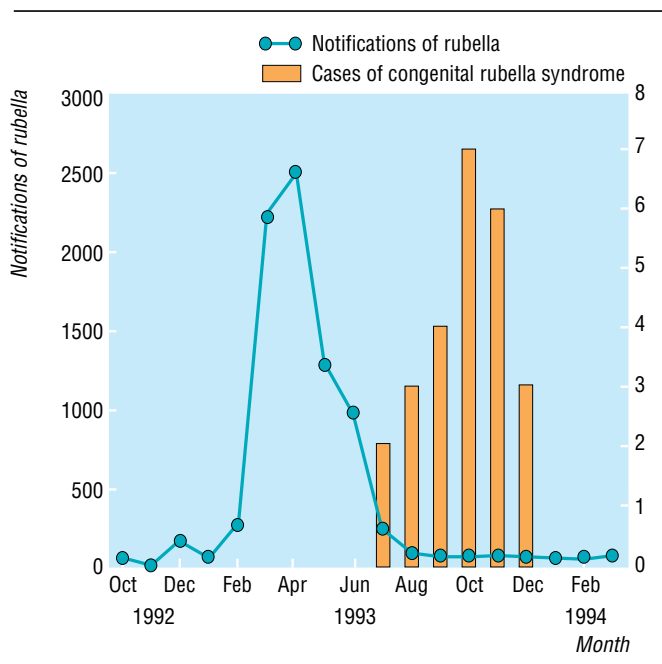

Fig 3 Notifications of rubella by month of diagnosis, and cases of congenital rubella by month of birth in epidemic in Greece, 1993. Source: National Statistical Service of Greece ${ }^{18}$ (notifications of rubella) and Panagiotopoulos et a ${ }^{22}$ (cases of congenital rubella syndrome)

older ages (fig 2) was documented in all the services studied. $^{20}{ }^{21}$ In 1993 the mean age of patients with rubella was 17 years and 64\% were 15 years or older $(\mathrm{n}=468)$, whereas in 1983 and 1986 the age distribution was similar to the prevaccination years. ${ }^{20}$ Although the number of notified cases was smaller in 1993 than in 1983 the incidence of rubella in people aged 15 years or more was higher in 1993 than in the 1983 epidemic, which was the largest recorded in Greece. ${ }^{20}$

Only sporadic cases of congenital rubella were reported in Greece in 1950-92: 1952 (one case), 1954-5 (five), 1974-85 ${ }^{13}, 1980$ (one), 1983 (three), and 1986-7 (four). ${ }^{\mathrm{w} 43-\mathrm{w} 49}$ A systematic surveillance system for congenital rubella syndrome has never existed, but an investigation of key health services by the Ministry of Health after the 1983 rubella epidemic concluded that "no problems appeared due to infection of pregnant women." ${ }^{\text {w50 }}$ An investigation of babies admitted to hospital with a diagnosis of congenital rubella was made after the 1993 epidemic, in which 25 serologically confirmed cases were recorded (IgM positive) - that is, 24.6 per 100000 live births in 1993 (table). ${ }^{22}$ All had serious symptoms and seven were known to have died within the 12 month period of investigation (table). ${ }^{22}$ The pattern of the congenital rubella epidemic followed closely that of the rubella epidemic, with a lag of approximately 6-7 months (fig 3). Infant mortality from congenital rubella syndrome, as recorded by the National Statistical Service of Greece, was 3.9 per 100000 live births in 1993 (four deaths), a higher rate than in previous years, but the numbers are small. ${ }^{19}$

\section{Discussion}

In this paper we synthesised the available information on rubella and congenital rubella in Greece, and we provided evidence that the rubella epidemic of 1993 affected young adults at a rate higher than in previous epidemics and led to the birth of an increased number of babies with congenital rubella syndrome, probably the largest number in Greece after 1950. This increase seems to be due to the inconsistent immunisation policies implemented for about 15 years. From around 1975 boys and girls aged 1 year received the measles, mumps, and rubella vaccine without policies to attain high vaccination coverage and to protect adolescents and women of childbearing age. It has been stressed that such immunisation practices may lead to an increase in the occurrence of congenital rubella, ${ }^{4-14}$ but this phenomenon has not been previously reported.

The absence of good quality data on rubella activity in Greece is an inherent problem. It is actually a component of the incident described: the introduction of rubella immunisation, not being part of a coherently designed policy, was not accompanied by the establishment of any surveillance system.

Notification data underestimate the true incidence but reflect secular trends and epidemic peaks. ${ }^{19}$ The shift of the age distribution of cases of rubella in 1993, with an increase in incidence among people aged 15 years or more, is confidently documented, given the magnitude of the effect (fig 2) and its consistency in different studies. ${ }^{20}{ }^{21}$ The cases of congenital rubella recorded in 1993 all had serious symptoms, were serologically confirmed, and were diagnosed within 12 months of the end of the rubella epidemic (table). ${ }^{22}$ Such severe cases are estimated to account for fewer than $50 \%$ of all cases of congenital rubella. ${ }^{23}$ The quality of data from previous years is probably poorer and underreporting even greater (for example, only small numbers of cases of congenital rubella were reported after the major epidemics of 1973 and 1983), but it is unlikely that a major epidemic of congenital rubella, comparable to that of 1993, took place without being mentioned in the published literature or official records. Deaths from congenital rubella syndrome are substantially underreported. Despite the small numbers, the marginal increase of mortality in 1993

\section{What is already known on this topic}

Vaccinating children aged 1 year against rubella interrupts transmission of the virus and increases the age at infection of non-immunised people

Theoretical concerns exist, backed by evidence from modelling, that if vaccination coverage is low this shift of age at infection can increase rubella incidence among older age groups and lead to an increase in congenital rubella

\section{What this paper adds}

The present study provides evidence that this phenomenon occurred in Greece, where immunisation of boys and girls aged 1 year with the measles, mumps, and rubella vaccine was introduced in the mid-1970s without policies to attain high vaccination coverage and to protect adolescents and young women

In 1993 a major rubella epidemic took place, affecting women of childbearing age at a rate higher than in previous epidemics

This was followed by the birth of the largest number of babies with congenital rubella syndrome recorded in the country 
compared with previous years is in line with other findings. Not all the studies on vaccination coverage and serologically detected immunity were adequately designed, but as a whole they probably reflect the true trends and order of magnitude of estimates, given the agreement of their results (see tables A and B on website). Exclusion of studies that documented methods inadequately or used non-representative samples does not change the picture (see tables A and B on website). The composite data of this paper, derived from several independent sources, are consistent in portraying different aspects of the same phenomenon.

A comprehensive policy for the prevention of congenital rubella syndrome is a public health priority in Greece. This must include the immunisation of young adults, a large proportion of whom are susceptible to rubella, along with systematic measures to achieve high vaccination coverage of children and adolescents. It must also include competent surveillance systems for rubella and congenital rubella syndrome and evaluation of immunisation programmes. Such a policy has not been adopted to date.

The incident described should serve as a cautionary note on the potential hazards of the introduction of rubella immunisation, especially in countries that have difficulty in assuring high vaccination coverage because of lack of resources or a limited tradition of public health. It is also a reminder of the need to sustain high vaccination coverage in countries with established immunisation programmes, particularly in view of the recent adverse publicity regarding the safety of the measles, mumps, and rubella vaccine. ${ }^{24}$

We thank Dr Sheena Nakou (Institute of Child Health, Athens for her assistance, Professor Manolis Kogevinas (Institut Municipal d' Investigació Mèdica, Barcelona), Dr Stuart Logan (Institute of Child Health, London), and Professor Nick Spencer (University of Warwick, Coventry) for their comments on earlier drafts of this paper.

Contributors: TP, the principal investigator, initiated and designed the study, discussed core ideas, collected data and carried out the systematic reviews, contributed to data analysis and interpretation of the findings, and wrote the paper. IA initiated the study, discussed core ideas and the study design, collected data, contributed to data analysis and interpretation of the findings, and edited the paper. EV-A discussed core ideas and the study design, collected data, contributed to data analysis and interpretation of the findings, and edited the paper. TP, IA, and EV-A will act as guarantors for the paper.

\section{How does herd immunity work?}

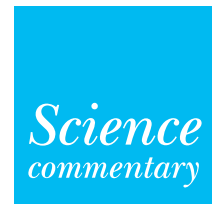

"Herd immunity" is the basis on which all national immunisation programmes are designed. It is the concept that not everybody in a population has to be immunised to protect everyone in that population. As long as a sufficient number of children are immunised against each disease for which there is a vaccine, protection against that disease will be conferred on everybody. The percentage of the population that must however be immunised depends on three factors: the infectivity of the disease, the vulnerability of the population, and environmental factors. ${ }^{1}$ In order to confer $100 \%$ protection in any community a disease such as measles, which is highly infectious, will require a larger number of
Funding: Institute of Child Health, Athens, Greece. Competing interests: None declared.

Cooper LZ. The history and medical consequences of rubella. Rev Infect Dis 1985;7(suppl 1):2-10S

2 Miller E, Cradock-Watson JE, Pollock TM. Consequences of confirmed maternal rubella at successive stages of pregnancy. Lancet 1982;2:781-4.

Best JM. Rubella vaccines: past, present and future. Epidemiol Infect 1991;107:17-30.

4 Knox EG. Theoretical aspects of rubella vaccination. Rev Infect Dis 1985;7(suppl 1):194-7S

5 Bart KJ, Orenstein WA, Preblud SR, Hinman AR. Universal immunization to interrupt rubella. Rev Infect Dis 1985;7(suppl 1):177-84S.

6 Knox EG. Strategy for rubella vaccination. Int J Epidemiol 1980;9:13-23.

7 Anderson RM, May RM. Vaccination against rubella and measles: quantitative investigation of different policies. J Hyg (Camb) 1983;90:259-325.

8 Hethcote HW. Measles and rubella in the United States. Am J Epidemiol 1983;117:2-13.

9 Van Druten JAM, de Boo T, Plantinga AD. Measles, mumps and rubella: control by vaccination. Dev Biol Stand 1986;65:53-63.

10 Dudjeon JA. Selective immunization: protection of the individual. Rev Infect Dis 1985;7(suppl 1):185-90S.

11 Bötiger M, Forsgren M. Twenty years' experience of rubella vaccination in Sweden: 10 years of selective vaccination (of 12-year-old girls and of women postpartum and 13 years of a general two-dose vaccination. Vaccine 1997;15:1538-44.

12 Center for Disease Control. Rubella prevention. Recommendations of the Immunization Practices Advisory Committee. MMWR Morb Mortal Wkly Rep 1990;39(RR-15):1-18.

13 A second dose of MMR vaccine for children in the United Kingdom. Commun Dis Rep CDR Wkly 1996;6:259.

14 Robertson SE, Cutts FT, Samuel R, Diaz-Ortega J-L. Control of rubella and congenital rubella syndrome (CRS) in developing countries. Part 2: vaccination against rubella. Bull World Health Organ 1997;75:69-80.

15 Cutts FT, Robertson SE, Diaz-Ortega J-L, Samuel R. Control of rubella and congenital rubella syndrome (CRS) in developing countries. Part 1: burden of disease from CRS. Bull World Health Organ 1997;75:55-68.

16 World Health Organisation. Health for all targets. The health policy for Europe. European Health for All Series, No 4. Copenhagen: WHO, 1991:31-3.

17 De la Malta I, De Wals P. Policies for immunization against rubella in European countries. Eur J Epidemiol 1988;4:175-80.

18 National Statistical Service of Greece. Monthly statistical bulletin (years 1960 to 1995). Athens: NSSG,

19 Panagiotopoulos T, Antoniadou I, Valassi-Adam E. Major epidemic of congenital rubella in Greece in 1993: a serious public health problem. Report on a study of the Institute of Child Health. Athens: Institute of Child Health; Dec 1995. (In Greek.)

20 Panagiotopoulos T, Antoniadou I, Antonopoulou E, Gogoglou V, Taousani S, Lakaki E, et al. Increase of age at infection in Attiki (Greece) during the rubella epidemic of 1993. Arch Hellenic Med 1996;13:211-9. (In Greek.)

21 Panagiotopoulos T, Antoniadou I, Delis D, Giannakos A, Chrysomallou P, Bartsokas C, et al. Increase of age at infection in the childhood population of Athens during the rubella epidemic of 1993. Ann Clin Paediatr Univ Atheniensis 1995;42:175-80. (In Greek.)

22 Panagiotopoulos T, Antoniadou I, Valassi-Adam E. Congenital rubella syndrome epidemic in Greece in 1993. A report of 25 confirmed cases. Paediatriki 1997;60:582-91. (In Greek.)

23 Orenstein WA, Preblud SR, Bart KJ, Hinman AR. Methods for assessing the impact of rubella infection. Rev Infect Dis 1985;7(suppl 1):22-8S

24 Wakefield AJ, Murch SH, Anthony A, Linnell J, Casson DM, Malik M, et al. Ileal-lymphoid-nodular hyperplasia, non-specific colitis and pervasive developmental disorder in children. Lancet 1998;351:637-41. (2 September 1999)

children to be immunised against it than, for example, mumps which is less contagious. A crowded inner city community will need a higher proportion of all vulnerable children to be immunised than a sparsely populated rural area. On average, to achieve $100 \%$ protection against measles in the United Kingdom the uptake of immunisation must be about $95 \%$, whereas in India uptake has to reach about $99 \%$ to reach the same level of protection. For meningitis it is apparent that there are more cases of the disease in winter than in summer. This suggests that environmental factors, and possibly cofactors such as the influenza virus, play a part in the generation of new cases of meningitis. 
The "effective reproduction rate" $(\mathrm{R})$ is the average number of new infections that each case generates. If $\mathrm{R}$ is 1 then a state of equilibrium exists. If $\mathrm{R}$ is less than 1 then the disease in question will eventually become extinct. For measles $\mathrm{R}$ is about 16 . This means that each case of measles can expect to generate about 16 new cases in a susceptible population. The aim of herd immunity is to reduce $\mathrm{R}$ to less than 1 for each disease thus stopping the disease from propagating in the community.

Over time, as the proportion of children who are immunised in a population increases, the number of new cases of a disease should drop. If, however, enough parents decide not to have their children vaccinated, more cases will start to appear and then the entire population is put at risk. Successful herd immunity relies on health workers and parents' cooperation to immunise sufficient numbers of children.

Despite recent further evidence of vaccine safety, health scares about the measles, mumps, and rubella vaccine have contributed to a $5 \%$ reduction in the number of children being immunised with this vaccine in the United Kingdom. This reduction is sufficient to allow the reproduction rate to start rising again, and as a result a new measles epidemic has been predicted in the United Kingdom within the next two years. ${ }^{2}$

Abi Berger science editor, BMJ

1 Begg NT, Gay NJ. Theory of infectious disease transmission and herd immunity. In: Balows A, Sussman M, eds. Topley and Wilson's microbiology and microbial infections. Vol 3. 9th ed. London: Edward Arnold, 1997.

2 Fall in MMR vaccine coverage reported as further evidence of vaccine safety is published. CDR Weekly 1999;9:227-30.

\title{
The SCOFF questionnaire: assessment of a new screening tool for eating disorders
}

\author{
John F Morgan, Fiona Reid, J Hubert Lacey
}

Eating disorders are among the most common psychiatric disorders in young women. Early detection and treatment improves prognosis, but presentation is often cryptic-for example, via physical symptoms in primary care. Ability to diagnose the condition varies and can be inadequate, ${ }^{1}$ and existing questionnaires for detection $^{23}$ are lengthy and may require specialist interpretation. No simple, memorable screening instruments are available for non-specialists. In alcohol misuse the CAGE questionnaire ${ }^{4}$ has proved popular with clinicians because of its simplicity. We developed and tested a similar tool for eating disorderswith questions designed to raise suspicion that an eating disorder might exist-before rigorous clinical assessment.

\section{Participants, methods, and results}

We developed five questions addressing core features of anorexia nervosa and bulimia nervosa using focus groups of patients with eating disorders and specialists in eating disorders; we tested the questions in a feasibility study of patients and staff at an eating disorders unit. None of these participants was involved in the subsequent study. We created the acronym SCOFF from the questions (box).

We recruited cases sequentially from referrals to a specialist clinic: 116 women aged 18-40 years who were confirmed as having either anorexia nervosa $(n=68)$ or bulimia $(n=48)$, according to the criteria specified in the Diagnostic and Statistical Manual of Mental Disorders, fourth edition. We recruited 96 women aged 18-39 as controls; these women, recruited through advertising by local colleges, were confirmed as not having an eating disorder. Cases and controls were asked the SCOFF questions orally; they also completed the eating disorder inventory ${ }^{3}$ and the BITE self rating scale for bulimia. ${ }^{2}$

\section{The SCOFF questions* \\ Do you make yourself Sick because you feel uncomfortably full? \\ Do you worry you have lost Control over how much you eat? \\ Have you recently lost more than One stone in a 3 month period? \\ Do you believe yourself to be Fat when others say you are too thin? \\ Would you say that Food dominates your life? \\ *One point for every "yes"; a score of $\geqslant 2$ indicates a likely case of anorexia nervosa or bulimia}

No significant differences existed between cases and controls for age or ethnicity. As expected, more cases than controls were in the highest socioeconomic groups $\left(\left(\mathrm{P}<0.001, \chi^{2}=47.4, \mathrm{df}=3\right)\right.$, and cases were more likely to be single, separated, or divorced $\left(\mathrm{P}<0.001, \chi^{2}=13.0, \mathrm{df}=1\right)$. Mean length of illness for cases was 8 years (SD 4.81; range 1-25). Mean body mass index (weight $(\mathrm{kg}) /\left(\right.$ height $\left.(\mathrm{m})^{2}\right)$ ) for controls, bulimic cases, and anorectic cases was 22.3 (SD 1.90), 24.4 (1.77), and 15.1 (0.76) respectively. All scores on the eating disorder inventory and the BITE scale were consistent with published data for women with or without eating disorders. ${ }^{2}{ }^{3}$

All participants found the questions and the term SCOFF acceptable. Setting the threshold at two or more positive answers to all five questions provided $100 \%$ sensitivity for anorexia and bulimia, separately and combined (all cases, 95\% confidence interval $96.9 \%$ to $100 \%$; bulimic cases, $92.6 \%$ to $100 \%$; anorectic cases, $94.7 \%$ to $100 \%$ ), with specificity of $87.5 \%$ (79.2\% to $93.4 \%$ ) for controls (table).

\section{Department of Psychiatry, St George's Hospital Medical School, London SW17 ORE \\ John F Morgan clinical research fellow $\mathrm{J}$ Hubert Lacey professor \\ Department of Public Health Sciences, \\ St George's \\ Hospital Medical \\ School \\ Fiona Reid \\ lecturer in medical statistics \\ Correspondence to: J F Morgan jmorgan@sghms. ac.uk}

BMJ 1999;319:1467-8 